\title{
Diatoms and pH Reconstruction
}

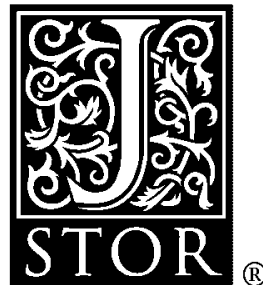

\author{
H. J. B. Birks; J. M. Line; S. Juggins; A. C. Stevenson; C. J. F. Ter Braak
}

Philosophical Transactions of the Royal Society of London. Series B, Biological Sciences, Vol. 327, No. 1240, Palaeolimnology and Lake Acidification (Mar. 12, 1990), 263-278.

Stable URL:

http://links.jstor.org/sici?sici=0080-4622\%2819900312\%29327\%3A1240\%3C263\%3ADAPR\%3E2.0.CO\%3B2-F

Philosophical Transactions of the Royal Society of London. Series B, Biological Sciences is currently published by The Royal Society.

Your use of the JSTOR archive indicates your acceptance of JSTOR's Terms and Conditions of Use, available at http://www.jstor.org/about/terms.html. JSTOR's Terms and Conditions of Use provides, in part, that unless you have obtained prior permission, you may not download an entire issue of a journal or multiple copies of articles, and you may use content in the JSTOR archive only for your personal, non-commercial use.

Please contact the publisher regarding any further use of this work. Publisher contact information may be obtained at http://www.jstor.org/journals/rsl.html.

Each copy of any part of a JSTOR transmission must contain the same copyright notice that appears on the screen or printed page of such transmission.

JSTOR is an independent not-for-profit organization dedicated to creating and preserving a digital archive of scholarly journals. For more information regarding JSTOR, please contact support@ jstor.org. 
Printed in Great Britain

\title{
Diatoms and $\mathrm{pH}$ reconstruction
}

\author{
By H. J. B. Birks ${ }^{1}$, J. M. Line ${ }^{2}$, S. Juggins ${ }^{3}$, A. C. Stevenson ${ }^{4}$ \\ AND C. J. F. TER BRAAK ${ }^{5}$ \\ ${ }^{1}$ Botanical Institute, University of Bergen, Allégaten 41, N-5007 Bergen, Norway \\ ${ }^{2}$ University of Cambridge Computer Laboratory, Pembroke Street, Cambridge CB2 3QG, U.K. \\ ${ }^{3}$ Palaeoecology Research Unit, Department of Geography, University College, 26 Bedford Way, London \\ WC1H $0 A P, U . K$. \\ ${ }^{4}$ Department of Geography, University of Newcastle upon Tyne, Newcastle upon Tyne NE1 7RU, \\ U.K. \\ ${ }^{5}$ Agricultural Mathematics Group, Wageningen, Box 100, 6700 AC Wageningen, The Netherlands, \\ and Research Institute for Nature Management, Box 46, 3956 ZR Leersum, The Netherlands
}

[Microfiche in pocket]

Palaeolimnological diatom data comprise counts of many species expressed as percentages for each sample. Reconstruction of past lake-water $\mathrm{pH}$ from such data involves two steps; (i) regression, where responses of modern diatom abundances to $\mathrm{pH}$ are modelled and (ii) calibration where the modelled responses are used to infer $\mathrm{pH}$ from diatom assemblages preserved in lake sediments. In view of the highly multivariate nature of diatom data, the strongly nonlinear response of diatoms to $\mathrm{pH}$, and the abundance of zero values in the data, a compromise between ecological realism and computational feasability is essential. The two numerical approaches used are (i) the computationally demanding but formal statistical approach of maximum likelihood (ML) Gaussian logit regression and calibration and (ii) the computationally straightforward but heuristic approach of weighted averaging (wA) regression and calibration.

When the Surface Water Acidification Project (SWAP) modern training set of 178 lakes is reduced by data-screening to 167 lakes, wA gives superior results in terms of lowest root mean squared errors of prediction in cross-validation. Bootstrapping is also used to derive prediction errors, not only for the training set as a whole but also for individual $\mathrm{pH}$ reconstructions by wA for stratigraphic samples from Round Loch of Glenhead, southwest Scotland covering the last 10000 years. These reconstructions are evaluated in terms of lack-of-fit to $\mathrm{pH}$ and analogue measures and are interpreted in terms of rate of change by using bootstrapping of the reconstructed $\mathrm{pH}$ time-series.

\section{INTRODUCTION}

Diatoms are good ecological indicators of lake-water $\mathrm{pH}$ (Battarbee et al. 1986). In recent years this feature has been exploited to reconstruct $\mathrm{pH}$ from diatom assemblages preserved in lake sediments (Battarbee I 984; Battarbee \& Charles I987) and a variety of numerical procedures have been developed for quantitative inference of $\mathrm{pH}$. Quantitative reconstruction of $\mathrm{pH}$ from diatoms is, in practice, a two-step process. First, the responses of modern diatoms to contemporary $\mathrm{pH}$ are modelled. This is a regression problem (ter Braak \& Looman 1987; ter Braak \& Prentice I988) and involves a modern, training set of diatom assemblages ('response' variables) from surface lake-sediment samples with associated $\mathrm{pH}$ data ('predictor' variable). 
Second, the modelled responses are used to infer past $\mathrm{pH}$ from the composition of fossil diatom assemblages. This is a calibration problem (ter Braak 1987a; ter Braak \& Prentice 1988).

There are at least five major ecological assumptions in quantitative, palaeoenvironmental reconstructions (Imbrie \& Webb I98I).

1. The taxa in the training set are systematically related to the physical environment in which they live.

2. The environmental variable to be reconstructed (in our case $\mathrm{pH}$ ) is, or is linearly related to, an ecologically important variable in the system of interest.

3. The taxa in the training set are the same as in the fossil data-set and their ecological responses have not changed significantly over the timespan represented by the fossil data. Contemporary patterns of diatom abundance in relation to $\mathrm{pH}$ can thus be used to reconstruct $\mathrm{pH}$ changes through time.

4. The mathematical methods used in regression and calibration adequately model the biological responses to the environmental variable of interest.

5. Environmental variables other than the one of interest (e.g. $\mathrm{pH}$ ) have negligible influence, or their joint distribution with the variable of interest in the fossil set is the same as in the training set.

Diatom data contain many taxa (ca. 100-300 taxa) and many zero values; values are commonly expressed as percentages of the total valves counted in a sample. They are thus closed, multivariate compositional data and have a constant-sum constraint. Diatom responses to $\mathrm{pH}$ are frequently nonlinear. These features confer important statistical properties on the data.

A variety of numerical procedures (reviewed by Battarbee (1984), Charles (1985) and Birks (1987)) have been used to reconstruct $\mathrm{pH}$ but none of these are fully satisfactory either theoretically or ecologically (Birks 1987; ter Braak \& van Dam 1989). They are nearly all variants of the basic multiple linear regression model and usually involve grouping diatoms into ecological categories (see, for example, Charles (1985); Davis \& Anderson (1985); Flower (1986); Charles \& Smol (1988)). ter Braak and van Dam (1989) introduced two procedures, maximum likelihood (ML) and weighted averaging (WA) regression and calibration (see also ter Braak $(1987 b))$. They are more sound theoretically and perform better than other, more widely used 'ad hoc' $\mathrm{pH}$ reconstruction techniques. These two procedures form the basis of this paper; wA regression and calibration are used for $\mathrm{pH}$ reconstructions within the Surface Water Acidification Project (SWAP).

\section{THE DATA}

\section{(a) The modern data}

The SWAP training set consists of diatom counts of 178 surface samples from lakes in England (five lakes), Norway (51), Scotland (60), Sweden (30) and Wales (32). It includes all taxa (267) that are present in at least two samples with an abundance of $1 \%$ or more in at least one sample and that are identified to species level or below. Abundances are expressed as percentages of the total diatom count (ca. 500 valves) for that sample. The sum of the percentages of taxa included range from $65.0 \%$ to $99.1 \%$ (mean $=92.6 \%$ ) of the total diatom count per sample.

The $\mathrm{pH}$ data for each lake are based on the arithmetic mean of $\left[\mathrm{H}^{+}\right]$(Barth 1975 ; cf. Middleton \& Rovers 1976; Charles 1985), after initial data screening (Munro et al., this 
symposium). Many lakes have $\mathrm{pH}$ data based on three or more readings (131 lakes), though some only have one $(32)$ or two (15) readings. The $\mathrm{pH}$ range is $4.33-7.25(\bar{x}=5.59$, median $=5.51$, standard deviation $($ s.d. $)=0.77$ ). Further details of the data and their taxonomic consistency are given by Munro et al. (this symposium).

\section{(b) The fossil data}

We use the data of Jones et al. (1989) from Round Loch of Glenhead (RLGH), Galloway, southwest Scotland for reconstruction purposes. The 101 samples from 0.3 to $256.5 \mathrm{~cm}$ in core RLGH3 cover the last 10000 years. They contain some taxa absent in the training set and vice versa. Only taxa present in both sets are included. These represent $72.8-98.7 \%$ $($ mean $=88.2 \%)$ of the total diatom count per sample in the core.

\section{THEORY AND METHODS}

(a) Notation

We use the following notation throughout; $x$ is the environmental variable to be reconstructed, in our case $\mathrm{pH} ; x_{i}$ is the value of $x$ in sample (in our case lake) $i$; $y_{i k}$ is the abundance of taxon $k$ in sample $i\left(y_{i k} \geqslant 0\right)(i=1, \ldots n$ lakes and $k=1, \ldots m$ diatom taxa); $\hat{x}_{i}$ is the estimated or inferred value of $x$ for sample $i$.

\section{(b) Maximum likelihood regression and calibration}

The basic idea (ter Braak \& van Dam I 989; ter Braak I $987 a, b$; ter Braak \& Prentice I 988) is that the relation between the abundance of a diatom taxon and $\mathrm{pH}$ can be modelled by an ecological response curve consisting of systematic and random (error) components. Such a curve is fitted to the training set by nonlinear regression. The response curves and their assumed error structure form a statistical model of diatom composition in relation to $\mathrm{pH}$. The curves for all taxa determine jointly what diatom composition is expected at a given $\mathrm{pH}$. This model of responses and their error structure is used to calculate the probability that a particular $\mathrm{pH}$ would occur with a given assemblage over the range of possible $\mathrm{pH}$ values. The $\mathrm{pH}$ that gives the highest probability is the ML estimate.

There are many types of ecological response curves. A compromise is necessary between ecological realism and simplicity (ter Braak \& van Dam 1989); the Gaussian unimodal response model with symmetric unimodal curves is a suitable compromise (ter Braak $1987 b$ ).

The Gaussian logit model is usually applied to presence-absence data (see, for example, ter Braak \& Looman (1986)). However, it can be used, as here, as a quasi-likelihood model for proportions and as an approximation to the more complex multinomial logit model (ter Braak \& van Dam i 989). The multinomial model can be difficult to fit and its parameters difficult to interpret because of indeterminacies (ter Braak I988).

Following ter Braak and van Dam (1989), we fitted a Gaussian logit model to all 229 taxa that occurred in six or more lakes in the training set by logit regression (with binomial error structure). (Oksanen et al. (1988) fitted the related Gaussian model with Poisson error structure.) From the Gaussian logit regression coefficients, the optimum $\left(\hat{u}_{k}\right)$, tolerance $\left(\hat{t}_{k}\right)$ and height of the peak $\left(\hat{c}_{k}\right)$ of the fitted Gaussian response curve were calculated (ter Braak \& Looman I 986, I 987), along with the approximate $95 \%$ confidence intervals for the estimated $u_{k}$ and the standard error of the estimated $t_{k}$ (ter Braak \& Looman I986, I987). 
For each taxon, the significance $(\alpha=0.05)$ of the Gaussian logit model was tested against the simpler linear-logit (sigmoidal) model by a residual deviance test. The significance $(\alpha=0.05)$ of the Gaussian logit regression coefficient $b_{2}$ against the null hypothesis $\left(b_{2} \geqslant 0\right)$ was also assessed by a one-sided $t$-test (ter Braak \& Looman I986, I987). If the null hypothesis was rejected in favour of $b_{2}<0$, the taxon's optimum was considered significant. If either the Gaussian unimodal model or the optimum were not significant, the linear logit model and its regression coefficient $b_{1}$, were tested against the null model that the taxon showed no relation to $\mathrm{pH}$, by using deviance and two-sided $t$-tests.

For taxa with estimated optima clearly outside the range of sampled $\mathrm{pH}$ values, and with a significant linear logit model, the optimum was assumed to be the lowest $\mathrm{pH}$ sampled for decreasing linear logit curves and the highest $\mathrm{pH}$ sampled for increasing linear logit curves. Some taxa had fitted curves with a minimum $\left(b_{2}>0\right)$ instead of a maximum. For these taxa a linear logit model was fitted and, for wA calibration (table 3), the optima were taken to be the lowest or highest $\mathrm{pH}$ in the training set for decreasing curves and increasing curves, respectively. The tolerances are defined only for taxa with unimodal response curves.

The response curves and their assumed error structure were then used in mL calibration to find the $\mathrm{pH}$ with the highest probability of producing the observed diatom assemblages for each sample in both training and fossil data sets. This was done by using an iterative Gauss-Newton numerical optimization procedure with Gallant's (1975) chopping rule for step-shortening. Estimates of wA were used as initial estimates. Some samples failed to converge, however, with this procedure.

Regression and calibration of $\mathrm{ML}$ are computer-intensive and liable to find local maxima rather than the overall maximum, especially when the taxon tolerances are very unequal. An alternative approach that is both simpler and computationally easier and has essentially the same aims as ML is WA regression and calibration (ter Braak \& van Dam 1989; ter Braak \& Prentice 1988).

\section{(c) Weighted averaging regression and calibration}

The idea behind wA (ter Braak $1987 b$ ) is that in a lake with a certain $\mathrm{pH}$ range, diatoms with their $\mathrm{pH}$ optima close to the lake's $\mathrm{pH}$ will tend to be the most abundant taxa present. A simple and ecologically reasonable estimate of a taxon's $\mathrm{pH}$ optimum is thus the average of all the $\mathrm{pH}$ values for lakes in which the taxon occurs, weighted by the taxon's relative abundance (wA regression). Conversely, an estimate of the lake's $\mathrm{pH}$ is the weighted average of the $\mathrm{pH}$ optima of all the taxa present (wA calibration). Taxa with a narrow $\mathrm{pH}$ tolerance or amplitude can, if required, be given greater weight in wA than taxa with a wide $\mathrm{pH}$ tolerance.

The wa estimate of a taxon's optimum (equivalent to abundance weighted mean (see, for example, Charles (1985); Charles \& Smol (1988)), centroid), $\hat{u}_{k}$, is:

$$
\hat{u}_{k}=\sum_{i=1}^{n} y_{i k} x_{i} / \sum_{i=1}^{n} y_{i k}
$$

and a taxon's tolerance, $\hat{t}_{k}$, or weighted standard deviation is:

$$
\begin{gathered}
\hat{t}_{k}=\left[\sum_{i=1}^{n} y_{i k}\left(x_{i}-\hat{u}_{k}\right)^{2} / \sum_{i=1}^{n} y_{i k}\right]^{\frac{1}{2}} . \\
{[40]}
\end{gathered}
$$


The estimated optima can be used to infer a lake's $\mathrm{pH}$ from its diatom assemblage (wA calibration) by:

$$
\hat{x}_{i}=\sum_{k=1}^{m} y_{i k} \hat{u}_{k} / \sum_{k=1}^{m} y_{i k}
$$

whereas a tolerance-weighted estimate would be:

$$
\hat{x}_{i}=\left(\sum_{k=1}^{m} y_{i k} \hat{u}_{k} / \hat{t}_{k}^{2}\right) /\left(\sum_{k=1}^{m} y_{i k} / \hat{t}_{k}^{2}\right) \text {. }
$$

The theory of wA and the conditions under which wA approximates ML are fully discussed by ter Braak (1985, I987b), ter Braak \& Looman (1986), ter Braak \& Barendregt (I986) and ter Braak \& Prentice (1988).

In wA reconstructions, averages are taken twice, once in wA regression and once in wA calibration. This results in shrinkage of the range of inferred $\mathrm{pH}$ values. To correct for this, a simple linear deshrinking was done by regressing the initial inferred values $\hat{x}_{i}$ for the training set on the observed values, $x_{i}$, by using the linear regression model, so-called 'classical regression':

$$
\text { initial } \hat{x}_{i}=a+b x_{i}+\epsilon_{i} \text {, }
$$

and

$$
\text { final } \hat{x}_{i}=\left(\text { initial } \hat{x}_{i}-a\right) / b \text {, }
$$

where $a$ is the intercept and $b$ is the slope of the linear regression (ter Braak 1988 ). ter Braak $\&$ van Dam (1989) discuss the importance of deshrinking. They used 'inverse' regression (where $x_{i}$ is regressed on initial $\hat{x}_{i}$ values) to 'deshrink', because this minimizes the root mean squared error in the training set. Classical regression deshrinks more than inverse regression (see, for example, Lwin \& Maritz (1982)); it takes inferred values further away from the mean. In our case, the mean lies in the $\mathrm{pH}$ interval where a lake's $\mathrm{pH}$ is very variable, and acidification studies require the reconstructions to be most precise at the lower end of the $\mathrm{pH}$ range in the training set. For that, classical regression is preferable (Martinelle 1970; Lwin \& Maritz 1982). This deshrinking regression was also done for ML calibration to ensure comparability between results from the two approaches.

\section{(d) Summary statistics}

The root mean square of the error (RMSE) $\left(x_{i}-\hat{x}_{i}\right)$ was calculated for the training set for comparison of the predictive abilities of ML, WA and weighted averaging with tolerance downweighting (WA(tol)). Wallach \& Goffinet (1989) discuss the value of RMSE as a means of evaluating how well a model can be expected to function as a predictive tool. The correlation $(r)$ between $x_{i}$ and $\hat{x}_{i}$ was also calculated. As RMSE is invariably under-estimated when based solely on the training set (ter Braak \& van Dam 1989; Oksanen et al. 1988), split-sampling or cross-validation (Stone 1974; Snee 1977; Picard \& Cook 1984) was used to derive a reliable estimate of prediction error and hence to evaluate the predictive abilities of the different methods. This involves randomly splitting the modern data into a training set and a test set, and ensuring that only taxa fulfilling the criteria of two or more occurrences and $1 \%$ or more in any one sample in the new training set are included.

\section{(e) Error estimation}

Bootstrapping, a computer-intensive resampling procedure (Efron 1982; Efron \& Gong I983; Diaconis \& Efron I983; Wallach \& Goffinet 1989) was used to derive RmSE of prediction 
for individual $\mathrm{pH}$ reconstructions. It also provides another estimate of the overall RMSE of prediction for the training set. The underlying theory is described in Appendix 1.

The idea is that in each of many bootstrap cycles (in our case 1000) a subset of training samples is selected randomly from the original training set to form a bootstrap training set of the same size as the actual training set. This mimics sampling variation in the training set. Sampling is with replacement, so that samples may be selected more than once. Typically some samples will not be selected, and these form a bootstrap test set. In each cycle, wA regression and calibration are used with the bootstrap training set to infer $\mathrm{pH}$ for the modern samples in the bootstrap test set. This parallels the use of test sets in cross-validation and provides another estimate of the RMSE of prediction (see Appendix 1). This estimate is less prone to bias (Efron I 982, I 983 ) because the bootstrap uses the full size of the training set rather than the smaller size used in cross-validation.

In each cycle wa calibration is also used to infer $\mathrm{pH}$ for the fossil samples. For each fossil sample, the standard deviation of inferred $\mathrm{pH}$ for all bootstrap cycles is calculated. A naive user of the bootstrap might think that this standard deviation, e.g. $s_{i 1}$, is an estimate of prediction error. It is not, because $s_{i 1}$ would approach zero if the size of the training set steadily increases. In fact, $s_{i 1}$ is that part of the prediction error that is due to the estimation error in the taxon parameters in the calibration formulae $\left(\hat{u}_{k}, \hat{t}_{k}\right)$. The other, often larger, part of the prediction error is due to variation in taxon abundances at a given value of $\mathrm{pH}$. (In the bootstrap cycles, the taxon abundances of a fossil sample were kept fixed so $s_{i 1}$ cannot catch this variation). The latter part, e.g. $s_{2}$, is estimated from the training set by the root mean square (across all training samples) of the difference between observed $\mathrm{pH}$ and the mean bootstrap $\mathrm{pH}$ in all bootstrap cycles when that sample is in the bootstrap test set. Whereas the first part of the error varies from fossil sample to fossil sample, the second part is constant. The estimated RMSE of prediction is the square root of the sum of squares of the two components (see Appendix 1). This procedure can also be applied to each training sample.

\section{(f) Computing}

Gaussian logit and linear logit regressions were done with GLIM (Payne I986); wA regression and calibration, ML calibration, and associated statistics were implemented by WACALIB 2.1 , a special purpose FORTRAN 77 program written by JML. It includes some subroutines from CANOCo (ter Braak 1988) written by CJF ter B. and M. O. Hill and an ML optimization subroutine written by CJF ter B. Detrended correspondence and canonical correspondence analyses were done by means of canoco 3.0 (C. J. F. ter Braak (unpublished)). Analogue analysis was implemented by the FORTRAN 77 program ANALOG 1.2 written by JML. Bootstrapping of wa estimates was done by using WAGALIB 2.4, an update of WAGALIB 2.1 incorporating bootstrapping subroutines written by CJF ter B. Bootstrapping of stratigraphic changes was done with THERRAD (Kitchell et al. 1987). All computations were done on an IBM PC/AT or compatible machines.

\section{RESULTS}

(a) Comparison of root mean squared error of prediction for different numerical procedures

When ML, WA and WA(tol) were applied to the full training set, the RMSE (table 1) suggest that there is little to be gained in terms of RMSE by using ML. Moreover 14 of the 178 training samples ( $\mathrm{pH}$ range 4.79-6.75) failed to converge with $\mathrm{ML}$, i.e. for these samples our numerical 
procedure was unable to find a single most likely $\mathrm{pH}$ value. Cross-validation with a training set of 130 and a test set of $4 \mathbf{8}$ lakes produced RMSE for the test set in the order $\mathrm{WA}<\mathrm{ML}<\mathrm{WA}(\mathrm{tol})$.

In a large, heterogeneous data set such as the 178-lake training set, it is possible that some samples are 'rogues' or atypical observations, for example with unusual diatom assemblages weakly related to $\mathrm{pH}$, with poor or unreliable $\mathrm{pH}$ data, or with environmental variables other than $\mathrm{pH}$ having a major influence on the diatom composition. A data-screening exercise was performed to detect potential 'rogues'.

TABle 1. RoOt MEAN SQUARED ERROR OF PREdiction (RMSE) FOR WEIGHTED AVERAging REGRESSION AND GALIBRATION WITH (WA(tol)) AND WITHOUT (WA) TOLERANGEDOWNWEIGHTING AND MAXIMUM LIKELIHOOD (ML) REGRESSION AND CALIBRATION AND THE CORRELATION $(r$ ) BETWEEN OBSERVED AND PREDIGTED PH BY USING DIFFERENT TRAINING SETS

\begin{tabular}{|c|c|c|c|c|}
\hline training set & & WA & $\mathrm{wA}(\mathrm{tol})$ & ML \\
\hline 178 lakes $\times 267$ taxa $(229$ in $\mathrm{ML})$ & $\begin{array}{l}\text { RMSE } \\
r\end{array}$ & $\begin{array}{l}0.343 \\
0.913\end{array}$ & $\begin{array}{l}0.324 \\
0.921\end{array}$ & $\begin{array}{l}0.341^{\mathrm{a}} \\
0.911\end{array}$ \\
\hline 130 lakes $\times 240$ taxa & $\begin{array}{l}\text { RMSE } \\
r\end{array}$ & $\begin{array}{l}0.353 \\
0.907\end{array}$ & $\begin{array}{l}0.338 \\
0.914\end{array}$ & $\begin{array}{l}0.361^{\mathrm{b}} \\
0.905\end{array}$ \\
\hline Test set 48 lakes $\times 240$ taxa & $\begin{array}{l}\text { RMSE } \\
r\end{array}$ & $\begin{array}{l}0.331 \\
0.915\end{array}$ & $\begin{array}{l}0.404 \\
0.849\end{array}$ & $\begin{array}{l}0.356 \\
0.894\end{array}$ \\
\hline $\begin{array}{l}172 \text { lakes } \times 267 \text { taxa } \\
(6 \text { 'rogues' deleted })\end{array}$ & $\begin{array}{l}\text { RMSE } \\
r\end{array}$ & $\begin{array}{l}0.323 \\
0.921\end{array}$ & $\begin{array}{l}0.301 \\
0.931\end{array}$ & - \\
\hline $\begin{array}{l}167 \text { lakes } \times 267 \text { taxa } \\
(225 \text { taxa in } \mathrm{ML}) \\
(11 \text { 'rogues' deleted })\end{array}$ & RMSE & 0.297 & 0.278 & $0.317^{\mathrm{c}}$ \\
\hline
\end{tabular}

In the first screening, a lake was deleted if it (i) formed an extreme outlier on any of the first four axes of a detrended correspondence analysis (Hill r 979) of the diatom data in the full training set; (ii) had a large (extreme $5 \%$ ) residual distance to the $\mathrm{pH}$-axis in a canonical correspondence analysis (ter Braak 989 ) of the diatom data with $\mathrm{pH}$ as the only environmental variable; (iii) had a high ( $>0.75 \mathrm{pH}$ units) difference between observed and inferred $\mathrm{pH}$ in both wA and WA(tol) reconstructions. Six lakes fulfilled all three criteria. The RMSE for wA and WA(tol) for the training set with these six deleted showed some improvement (table 1). In a second screening of the reduced training set (172 lakes), a further five lakes now fulfilled two or three of the above criteria for deletion. When these five were also deleted, the RMSE for wA (0.297), WA (tol) (0.278), and ML (0.317) all showed further improvement (table 1). No lakes appeared to be obvious rogues within the reduced training set of 167 when screened again.

For $\mathrm{pH}$ reconstructions at RLGH and all other SWAP sites, this reduced training set of 167 lakes is used. This set has a $\mathrm{pH}$ range of $4.33-7.25(\bar{x}=5.56$, median $=5.27$, s.d. $=0.77)$ and 262 taxa.

A series of calibration experiments was done by using this training set to compare different regression and calibration procedures (table 2 ). Besides wA regression and calibration with and 

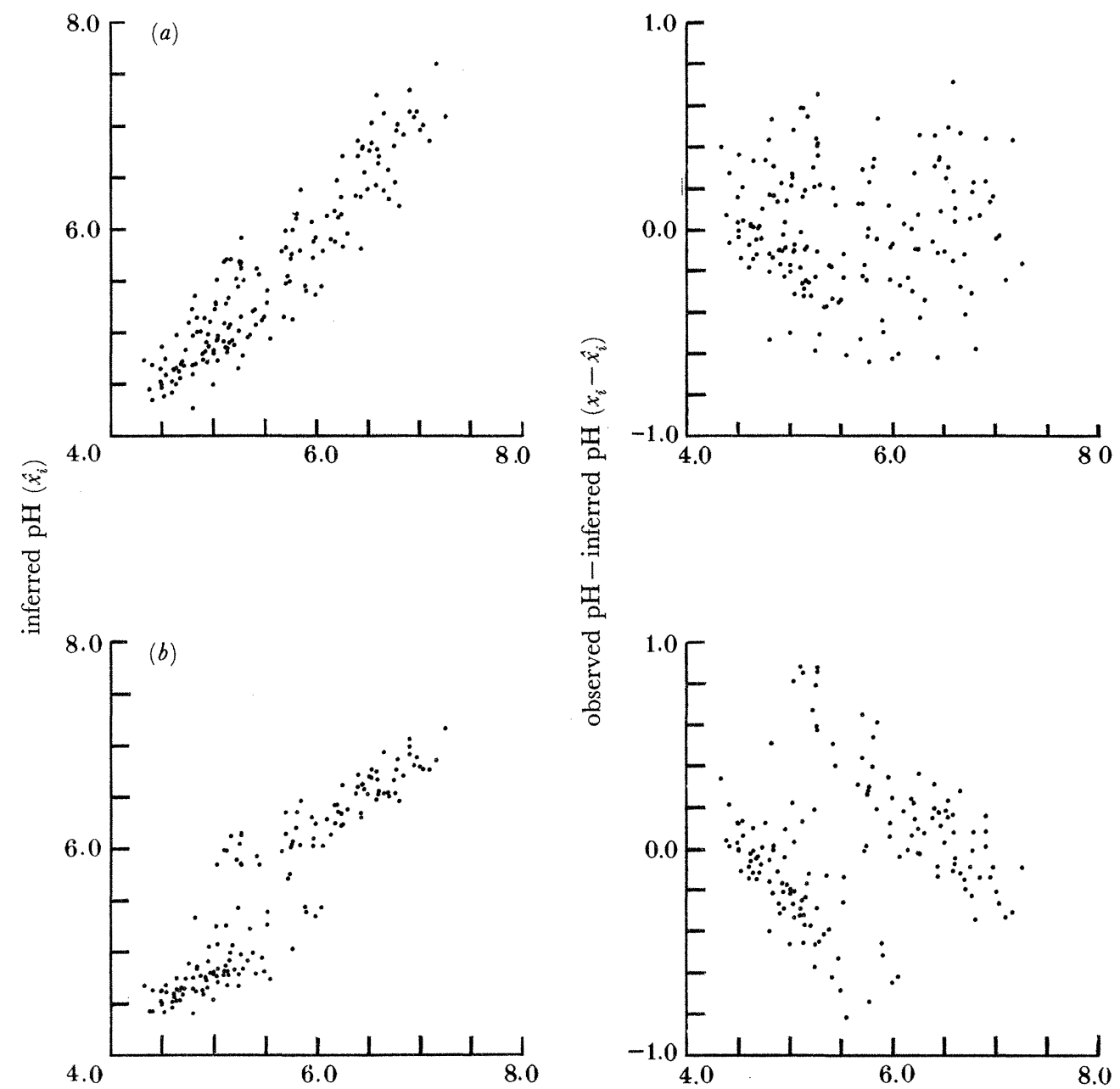

observed $\mathrm{pH}\left(x_{i}\right)$

FIGURE 1. Plots of inferred $\mathrm{pH}\left(\hat{x}_{i}\right)$ against observed $\mathrm{pH}\left(x_{i}\right)$ (left hand plots) and of the differences $\left(x_{i}-\hat{x}_{i}\right)$ against observed $\mathrm{pH}$ (right-hand plots) for $\mathrm{pH}$ inferences derived from $(a)$ weighted averaging and $(b)$ maximum likelihood regression and calibration.

TABLE 2. RoOT MEAN SQUARED ERROR OF PREDIGTION (RMSE) AND GORRELATION $(r$ ) BETWEeN OBSERVED AND INFERRED $\mathrm{PH}$ WHEN DIFFERENT REGRESSION AND GALIBRATION PROCEDURES ARE USED WITH THE 167 LAKE TRAINING SET

$\begin{array}{clccc}\begin{array}{c}\text { regression } \\ \text { procedure }\end{array} & \begin{array}{l}\text { calibration } \\ \text { procedure }\end{array} & \begin{array}{c}\text { number } \\ \text { of taxa }\end{array} & \text { RMSE } & r \\ \text { WA } & \text { WA } & 274 & 0.297 & 0.993 \\ \text { WA } & \text { WA(tol) } & 274 & 0.278 & 0.941 \\ \text { ML } & \text { WA } & 224 & 0.294 & 0.934 \\ \text { ML } & \text { WA(tol) } & 224 & 0.282 & 0.939 \\ \text { ML } & \text { WA } & 168^{\mathrm{a}} & 0.290 & 0.936 \\ \text { ML } & \text { WA(tol) } & 168^{\mathrm{a}} & 0.292 & 0.935 \\ \text { ML } & \text { ML } & 225 & 0.317 & 0.921\end{array}$

${ }^{a}$ All taxa with statistically significant relation to $\mathrm{pH}$ (see table 4). 
without tolerance downweighting and ML regression and calibration, 'hybrid' procedures were used with taxon optima and tolerances estimated by ML regression but by using wA (with and without tolerance downweighting) calibration (see, for example, Juggins (1988); Oksanen et al. ( 1988$)$ ) and all taxa and only those with a significant relation to $\mathrm{pH}$. The overall conclusion is that ML regression and calibration perform the worst (cf. ter Braak \& van Dam 1989), but that all the other procedures perform about equally well, as judged by RMSE. In terms of RMSE there seems little advantage in using $\mathrm{ML}$ regression compared with wA regression. Plots of inferred $\mathrm{pH}$ $\left(\hat{x}_{i}\right)$ against observed $\mathrm{pH}\left(x_{i}\right)$ and of the differences $\left(x_{i}-\hat{x}_{i}\right)$ against $x_{i}$ for wA and ML are shown in figure 1. In wA there is no systematic bias (cf. Oksanen et al. 1988) except for a tendency for the differences to be greatest in the $\mathrm{pH}$ range 5.3-6.6, and lowest at the extremes. These high differences all occur in poorly buffered lakes where small seasonal changes in alkalinity can cause large variations in $\mathrm{pH}$. In the absence of multiple $\mathrm{pH}$ measurements, estimation of a meaningful mean $\mathrm{pH}$ is impossible (Flower 1986). In $\mathrm{ML}$ two clusters emerge and $\mathrm{pH}$ estimates for ten lakes failed to converge, all in the $\mathrm{pH}$ range $4.79-5.89$.

TABLE 3. ROOT MEAN SQUARED ERROR OF PREDIGTION FOR TEN GROSS-VALIDATION EXPERIMENTS USING FOUR RANDOMLY SELEGTED TEST SETS OF 50 LAKES, FOUR RANDOMLY SELEGTED TEST SETS OF 40 LAKES, ONE RANDOMLY SELEGTED TEST SET OF 67 LAKES AND ONE RANDOMLY SELEGTED TEST SET OF 47 LAKES

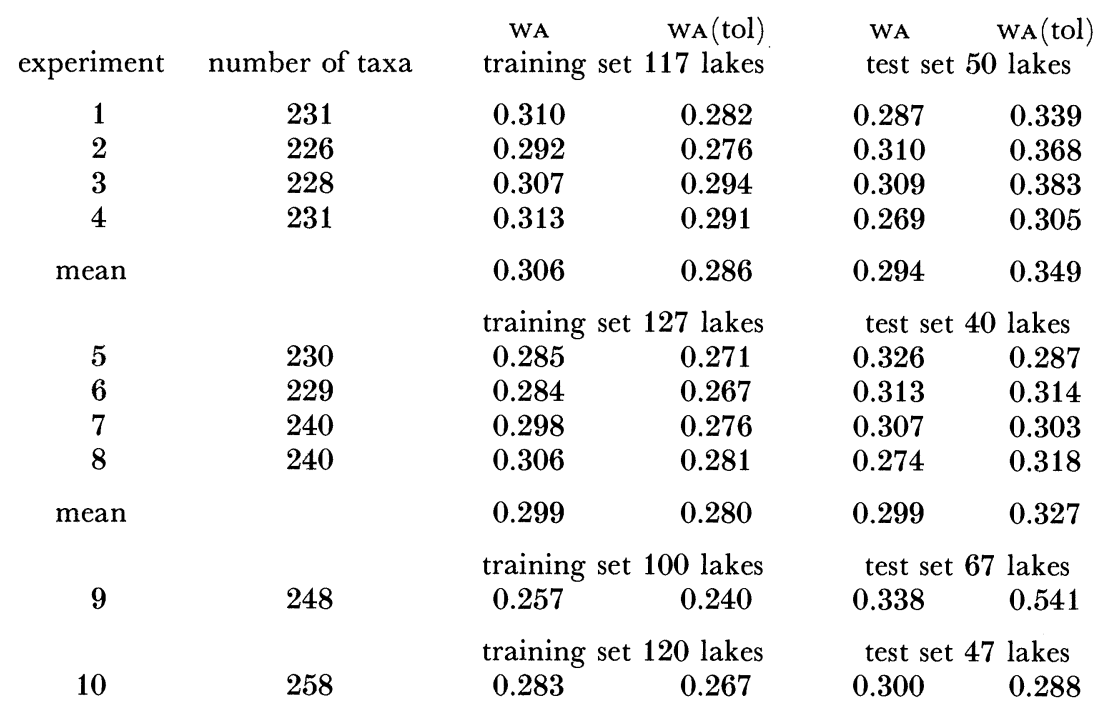

In light of the RMSE results (table 2) and plots of $x_{i}$ against $\hat{x}_{i}$ and of $\left(x_{i}-\hat{x}_{i}\right)$ against $x_{i}$ (not presented here) for these calibration experiments, wA regression and calibration with and without tolerance downweighting were selected for $\mathrm{pH}$ reconstructions at RLGH and all other SWAP lakes because of their low RMSE, their computational ease, and their robustness.

Ten cross-validation experiments were done to derive more reliable RMSE for WA and WA(tol), by using four randomly selected test sets of 50 lakes, four test sets of 40 lakes, a single test set of 67 lakes and one test set of 47 lakes (table 3 ). The RMSE for test sets in these experiments were $0.287-0.338$ (mean $=0.308$ ) for wA and 0.287-0.541 (mean $=0.376)$ for wA(tol). This indicates that WA has a lower prediction error in test sets than wA(tol). This error is, as ter Braak \& van Dam (1989) emphasize, the 'appropriate benchmark to compare methods' because all errors are considered (see also Oksanen et al. (1988)). 


\section{(b) Comparison of the $\mathrm{pH}$ optima and tolerance estimates}

The basis for these calibration experiments is the estimates of the taxon parameters. The wA and ML estimated optima and tolerances for all taxa in the 167-lake training set are listed in table 4 (see microfiche), along with each taxon's maximum value, number of occurrences, shape of response curve, $95 \%$ confidence intervals of the ML-estimated optimum, standard error of the ML-estimated tolerance, curve height, literature $\mathrm{pH}$ category, and statistical relation to $\mathrm{pH}$. Ecological discussion of these estimates will be presented in a subsequent SWAP publication. Of the 225 taxa (in six or more lakes) used for ML regression, 88 have unimodal curves with maxima, 78 have sigmoidal curves, 53 show no pattern, five have unimodal curves with minima and one failed to converge. A significant unimodal (88) or sigmoidal (78) response to $\mathrm{pH}$ is seen in 166 taxa. Of the 58 taxa with non-significant $\mathrm{pH}$ relations, only one has a fitted curve peak $\left(\hat{c}_{k}\right)>1 \%$ and only 15 have maximum values in the training set $>2.5 \%$ (range $=1.03-4.92 \%$ ). As $74 \%$ of the taxa have a significant relation with $\mathrm{pH}$, this provides strong confirmation for the assumption of Davis \& Smol (I986) 'that there is a good statistical relation between $\mathrm{pH}$ and relative abundance of diatoms.' In the sampled $\mathrm{pH}$ range (4.33-7.25) wA estimates of optima are close to the ML estimates, although wA consistently but very slightly underestimates optima compared to ML. This slight bias is, in part, due to the overrepresentation of acid lakes in the training set, because wA estimates are sensitive to the distribution of $x_{i}$ (ter Braak \& Looman 1986, I987). Major differences occur, however, at the extreme ends. At low $\mathrm{pH}$, wa overestimates the optimum, whereas at high $\mathrm{pH}$ it underestimates it, because of truncation of the taxon response curves at the edges of the $\mathrm{pH}$ gradient. As a result of this inevitable truncation, wA compresses estimates of optima towards the centroid of the sampled $\mathrm{pH}$ gradient (Oksanen et al. i 988 ).

Estimates of tolerances by WA are almost all underestimated compared with $\mathrm{ML}$, with a range of wA tolerances from $c a .0 .2$ to $0.75 \mathrm{pH}$ units and an $\mathrm{ML}$ range of $0.2-1.8 \mathrm{pH}$ units. For taxa with $\mathrm{ML}$ tolerances less than $0.75 \mathrm{pH}$ units, wA provides reliable estimates, but at higher values WA systematically underestimates the tolerance (Oksanen et al. I988). Many of the taxa with no significant relation to $\mathrm{pH}$ (table 4) have ML estimated tolerances of more than $1 \mathrm{pH}$ unit, suggesting a range of occurrence over at least $4 \mathrm{pH}$ units.

\section{(c) Reconstructions of $\mathrm{pH}$ for Round Loch of Glenhead}

The wA, wA(tol), and $\mathrm{ML} \mathrm{pH}$ reconstructions for RLGH are shown in figure 2 . The two wA reconstructions are closely parallel; 34 samples failed to converge in ML calibration.

\section{Evaluation of Regonstrugted pH values}

All quantitative palaeoenvironmental reconstruction procedures produce a result, but there is no simple means of evaluating how reliable it is. In addition to overall performance measures like RMSE calculated once from test sets, it is desirable to assess the reliability of individual reconstructed values. Two means towards this end are (i) measures of lack-of-fit of diatom assemblages to $\mathrm{pH}$ and (ii) estimated mean squared errors for each inferred $\mathrm{pH}$.

\section{(a) Lack-of-fit to $\mathrm{pH}$ and analogue measures}

In the screening of the training data we used the squared residual distance of the modern samples to the $\mathrm{pH}$ axis in a canonical correspondence analysis of the diatom data as a criterion 


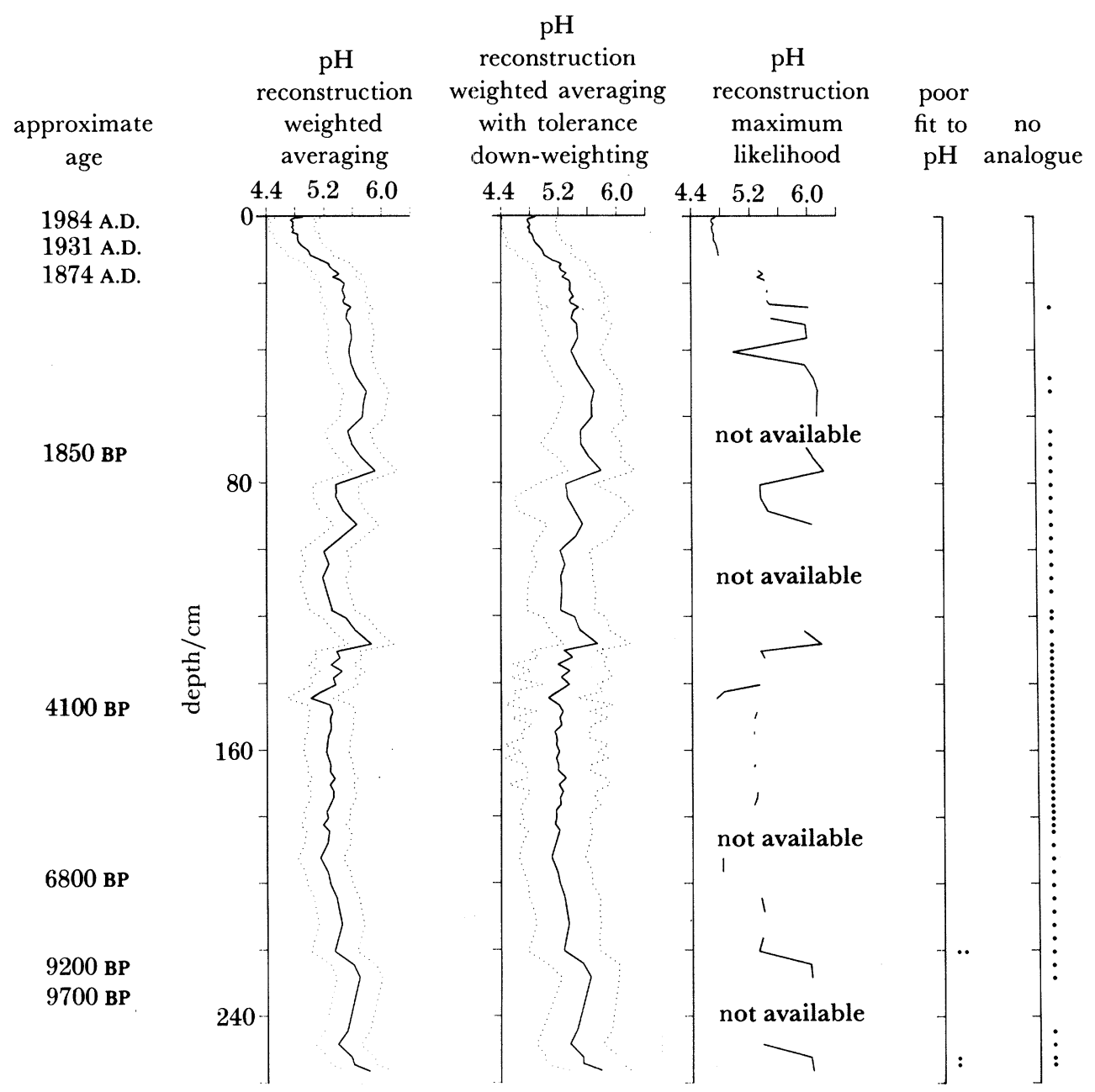

Figure 2. Reconstructed $\mathrm{pH}$ values for Round Loch of Glenhead plotted against depth (solid lines). The reconstructions are based on weighted averaging, tolerance-downweighted weighted averaging and maximum likelihood procedures. The RMSE of prediction for the weighted averaging estimates are shown as dotted lines. Samples with poor $(\cdot)$ or very poor $(\cdot \cdot)$ fit and those lacking close modern analogues in the SWAP trainingset $(\cdot)$ are indicated.

of lack-of-fit to $\mathrm{pH}$. Samples with a high residual distance from the $\mathrm{pH}$ axis have a poor fit to pH. Fossil, so-called passive, samples can also be positioned on this axis by means of transition formulae (ter Braak 1988). Any fossil sample whose residual distance is equal to or larger than the residual distance of the extreme $5 \%$ of the training set is considered to have a 'very poor' fit to $\mathrm{pH}$, and those with values equal to or larger than the extreme $10 \%$ are deemed to have a 'poor' fit. One sample at RLGH $(220.5 \mathrm{~cm})$ has a very poor fit, and two $(252.5,254.5 \mathrm{~cm}$ ) have poor fits (figure 2$)$.

A reconstructed $\mathrm{pH}$ value is likely to be more reliable if the fossil sample in question has close modern analogues within the training set. Every fossil sample at RLGH was compared with all samples in the training set by using squared $X^{2}$ distance as a dissimilarity measure (Prentice 1980). This is:

$$
d_{i j}^{2}=\sum_{k=1}^{m}\left[\left(y_{i k}-y_{j k}\right)^{2} /\left(y_{i k}+y_{j k}\right)\right]
$$

where $y_{i k}$ is the proportion of diatom taxon $k$ in sample $i$ and $d_{i j}$ is the $X^{2}$ distance between samples $i$ and $j$. 
Any fossil sample that has a minimum $d_{i j}>0.45$ appears to lack a close modern analogue in the training set (H. J. B. Birks, unpublished results). All RLGH samples below $48.5 \mathrm{~cm}$ fall in this category, as does the $27.3 \mathrm{~cm}$ sample (figure 2). This lack of modern analogues results, in part, from the abundance of Melosira arentii at RLGH, a taxon absent from the training set, and, in part, from the rarity of analogous, pristine, naturally acid but not acidified lakes in the SWAP study areas that could be sampled for the training set.

\section{(b) Estimated root mean squared error for $\mathrm{pH}$ reconstructions}

The RMSE of prediction for the training set, estimated by bootstrapping, are as follows:

$\begin{array}{ccc} & \text { WA } & \text { WA(tol) } \\ \text { RMSE } s_{i 1} & 0.072 & 0.305 \\ s_{2} & 0.312 & 0.371 \\ \text { RMSE prediction } & 0.320 & 0.480\end{array}$

The first error component is small for wa but large for wa(tol). The training set is thus clearly adequate to yield reliable estimates of the taxon parameters in the wa calibration formula $\left(\hat{u}_{k}\right)$, but is probably not large enough for reliable estimation of the tolerances $\left(\hat{t}_{k}\right)$ used in WA(tol).

The RMSE of prediction for the RLGH samples are plotted in figure 2 for wA and wA(tol). The RMSE for individual RLGH samples varies from 0.314 to 0.322 (WA) and 0.374 to 0.798 for wA (tol) and, for individual training samples, 0.314 to 0.376 for wA and 0.373 to 0.915 for $\mathrm{wA}(\mathrm{tol})$. These RMSE estimates indicate that there is no advantage in using tolerancedownweighting in wA calibration with this training set.

\section{Discussion}

(a) Procedures for $\mathrm{pH}$ reconstruction

Several conclusions emerge from our analyses (see also ter Braak \& van Dam (1989)). Regression and calibration by wA can now replace earlier 'ad hoc' methods for $\mathrm{pH}$ reconstruction; WA is ecologically more realistic, statistically more robust, and numerically more accurate than other methods. Although some 'ad hoc' methods may produce lower apparent RMSE, these error estimates are not based on rigorous error-estimation procedures such as cross-validation or bootstrapping, but on regression statistics derived solely for training sets. As ter Braak \& van Dam (1989) emphasize, RMse based on training sets alone give an overoptimistic idea of prediction and performance error. In all our cross-validation experiments, RMSE for test sets is larger than for training sets (see also Juggins (I 988); Oksanen et al. (1988)). In the SWAP training set the apparent RMSE for WA is 0.297 whereas the more realistic RMSE are 0.308 (cross-validation) and 0.320 (bootstrapping).

Although wA with tolerance-downweighting gives a lower apparent RMSE $(0.278)$ than wA, tolerance-weighting does not improve RMSE in cross-validation (0.376) or bootstrapping $(0.480)$. We therefore recommend simple wa regression and calibration with classical regression deshrinking as the easiest and most reliable $\mathrm{pH}$ reconstruction procedure currently available.

The overall RMSE is 0.320 for wA of the 167-lake training set. Standard errors of prediction for individual training samples and fossil samples at RLGH vary from 0.314 to 0.376 . As lake 
$\mathrm{pH}$ has inherent seasonal and annual variation and as there are errors in measuring $\mathrm{pH}$, particularly at low ionic-strength water, further reductions in prediction errors seem unlikely. Compared with other $\mathrm{pH}$ training sets (reviewed by ter Braak \& van Dam (I989)) this RMSE for a large $(n=167)$ training set is lower than is usually found. This is probably because the diatom assemblages are all from surficial sediments collected at or near the deepest part of the lake, many of the lakes have multiple $\mathrm{pH}$ determinations, the diatom taxonomy has been carefully harmonized as a result of SWAP taxonomic workshops (Munro et al., this symposium) and the training set was screened by using three different numerical techniques; 11 'rogue' lakes were detected and deleted.

It is surprising that the theoretically more rigorous approach of $\mathrm{ML}$ regression and calibration did not perform as well in terms of RMSE as the simpler, approximating approach of wA. This is probably because ML uses more of the data, especially the absences (which wA ignores) and the precise percentage values. The problem of no-analogues and of assemblages containing diatoms of contrasting affinities are therefore more serious in ML than in wA. Although the RLGH samples had about the same amount of lack-of-fit as the modern samples, the lack-offit was of a different kind than in the modern samples, as the no-analogue measure showed. It is therefore unsafe to rely on the quantitative aspects of an assemblage as heavily as ML does. By its very nature, ML is more susceptible to 'rogues' than wA. Although we were able to eliminate 11 rogues from the original training set, the computational demands of recomputing taxon optima and tolerances for different screened versions of the training set prevented further screening of the data for samples that are possible 'rogues' in ML regression and calibration. The training set is thus critically screened only for wA.

Regression and calibration by wA have several advantages over more widely used $\mathrm{pH}$ inference techniques such as Index B (R.enberg \& Hellberg 1982) and multiple regression of pH categories (see, for example, Flower (1986); Charles (1985); Charles \& Smol (1988)). Besides a lower Rmse (ter Braak \& van Dam 1989), the main advantage of wA is that there is no need to assign diatom taxa to $\mathrm{pH}$-preference categories. As Battarbee (1984) discusses and Holmes et al. (1989) clearly demonstrate, there are many problems in categorizing taxa, and the particular decision as to which category a taxon is assigned can markedly influence $\mathrm{pH}$ inferences by using Index B or multiple regression; wA is free of such problems. It uses the available data on the abundances of individual taxa in relation to $\mathrm{pH}$ in the training set. Moreover, because of the simple calculations involved in WA, it is possible to use bootstrapping to derive standard errors of predictions. Bootstrapping is, in theory, possible for $\mathrm{ML}$, but, in practice, is computationally prohibitive. Individual standard errors of prediction for $\mathrm{pH}$ reconstructions from fossil assemblages can be valuable in avoiding misinterpretation of inferred $\mathrm{pH}$ values.

\section{(b) Reconstructions of $\mathrm{pH}$ at Round Loch of Glenhead}

The reconstructed $\mathrm{pH}$ history at RLGH (figure 2) shows little change from the late-glacial about 10000 years ago to about 4100 years before present $(\mathrm{BP})(142 \mathrm{~cm})$. Reconstructed pH varied from 5.4 to 5.8 in the late-glacial and earliest Holocene, but by $9200 \mathrm{BP}(224 \mathrm{~cm})$ it stabilized to about 5.2-5.4. Between 4100 and $1850 \mathrm{BP}(72 \mathrm{~cm})$ there were short-lived fluctuations, probably associated with inwashing of material from the catchment (Jones et al. I989). Lake acidity changed little (5.3-5.7) until about 1870 A.D. when, between $17.3 \mathrm{~cm}$ (1874) and $7.3 \mathrm{~cm}$ (1931), $\mathrm{pH}$ dropped by over 0.5 units. Reconstructed $\mathrm{pH}$ values are never 
below 5.0 until about $1900(11 \mathrm{~cm})$. Jones et al. (1989) conclude that this marked change in lake acidity resulted from an increase in deposition of strong acids from the atmosphere.

The null hypothesis that the rate of $\mathrm{pH}$ change per unit depth between 1874 and 1931 $(17.3-7.3 \mathrm{~cm})$ is no different from the rates of $\mathrm{pH}$ change in pre acid-deposition times $(17.3-256-5 \mathrm{~cm})$ was tested by using bootstrapping of the reconstructed $\mathrm{pH}$ time-series to generate empirical probability distributions of $\mathrm{pH}$ change with depth. The $\mathrm{pH}$ time-series was resampled randomly and with replacement 1000 times to create temporally-ordered data sequences of the same thickness as the interval of interest by using the time-duration or elapsedtime test of Kitchell et al. (1987). As the time-series contains unequal depth intervals between $\mathrm{pH}$ estimates, it is not possible for each bootstrapped time-series to contain exactly $10 \mathrm{~cm}$. Instead samples are added to the time-series until the depth interval equals or exceeds the specific depth interval being tested. The observed rate of $\mathrm{pH}$ change at the time of increased acidic deposition is significantly different $(\alpha=0.021)$ from expectation. The null hypothesis is thus rejected, suggesting that the most rapid $\mathrm{pH}$ change per unit depth over the last 10000 years occurred between 1874 and 1931 at RLGH, the very time of increased acid deposition.

This research has been supported in part by SWAP, NAVF, and IBM (Norway). We are grateful to all SWAP diatomists for providing the training set, to Martin Munro for data-base management; to Rick Battarbee, John Boyle, Roger Flower and Viv Jones for valuable discussions; to Hilary Birks and John Kingston for commenting on earlier versions of the manuscript; to Sylvia Peglar and Siv Haugen for technical assistance; to Jennifer Kitchell and Norman MacLeod for providing THERRAD and to H. van der Voet for useful discussions about calibration and bootstrapping.

\section{REFERENGES}

Barth, E. F. 1975 Average pH. J. Wat. Pollut. Control Fed. 47, 2191-2192.

Battarbee, R. W. 1984 Diatom analysis and the acidification of lakes. Phil. Trans. R. Soc. Lond. B 305, 451-477.

Battarbee, R. W. \& Charles, D. F. 1987 The use of diatom assemblages in lake sediments as a means of assessing the timing, trends, and causes of lake acidification. Prog. phys. Geog. 11, 552-580.

Battarbee, R. W., Smol, J. P. \& Merliäinen, J. 1986 Diatoms as indicators of pH: an historical review. In Diatoms and lake acidity (ed. J. P. Smol, R. W. Battarbee, R. B. Davis \& J. Meriläinen), pp. 5-14. Dordrecht: Dr W. Junk.

Birks, H. J. B. 1987 Methods for $\mathrm{pH}$-calibration and reconstruction from palaeolimnological data: procedures, problems, potential techniques. Proceedings of the Surface Water Acidification Project (SWAP) mid-term review conference, Bergen 22-26 June 1987, pp. 370-380. London: SWAP.

Charles, D. F. I $_{95}$ Relationships between surface sediment diatom assemblages and lake water characteristics in Adirondack lakes. Ecology 66, 994-1011.

Charles, D. F. \& Smol, J. P. I 988 New methods for using diatoms and chrysophytes to infer past pH of lowalkalinity lakes. Limnol. Oceanogr. 33, 1451-1462.

Davis, R. B. \& Anderson, D. S. 1985 Methods of $\mathrm{pH}$ calibration of sedimentary diatom remains for reconstructing history of $\mathrm{pH}$ in lakes. Hydrobiologia 120, 69-87.

Davis, R. B. \& Smol, J. P. 1986 The use of sedimentary remains of siliceous algae for inferring past chemistry of lake water-problems, potential and research needs. In Diatoms and lake acidity (ed. J. P. Smol, R. W. Battarbee, R. B. Davis \& J. Meriläinen), pp. 291-300. Dordrecht: Dr W. Junk.

Diaconis, P. \& Efron, B. 1983 Computer-intensive methods in statistics. Scient. Am. 248(5), 96-109.

Efron, B. I982 The jackknife, the bootstrap, and other resampling plans. SIAM NSF-CBMS Monograph 38, 1-92.

Efron, B. 1983 Estimating the error rate of a prediction rule: improvement on cross-validation. J. Am. statist. Ass. 78, 316-331.

Efron, B. \& Gong, G. 1983 A leisurely look at the bootstrap, the jackknife, and cross-validation. Am. Statist. 37, $36-48$.

Flower, R. J. 1986 The relationship between surface sediment diatom assemblages and $\mathrm{pH}$ in 33 Galloway lakes: some regression models for reconstructing $\mathrm{pH}$ and their application to sediment cores. Hydrobiologia 143, 93-103. 
Gallant, A. R. 1975 Nonlinear regression. Am. Statist. 29, 73-81.

Hill, M. O. 1979 DECORANA - a FORTRAN program for detrended correspondence analysis and reciprocal averaging. Cornell University, Ithaca, New York: Section of ecology and systematics.

Holmes, R. W., Whiting, M. C. \& Stoddard, J. L. 1989 Changes in diatom-inferred $\mathrm{pH}$ and acid neutralizing capacity in a dilute, high elevation, Sierra Nevada lake since A.D. 1825. Freshwater Biol. 21, 295-310.

Imbrie, J. \& Webb, T. III I98I Transfer functions: calibrating micropaleontological data in climatic terms. In Climatic variations and variability: facts and theories (ed. A. Berger), pp. 125-134. Dordrecht: D. Reidel.

Jones, V. J., Stevenson, A. C. \& Battarbee, R. W. 1989 Acidification of lakes in Galloway, South West Scotland: a diatom and pollen study of the post-glacial history of the Round Loch of Glenhead. J. Ecol. 77, 1-23.

Juggins, S. 1988 A diatom/salinity transfer function for the Thames Estuary and its application to waterfront archaeology. Ph.D. thesis, University of London.

Kitchell, J. A., Estabrook, G. \& MacLeod, N. 1987 Testing for equality of rates of evolution. Paleobiology 13, $272-285$.

Lwin, T. \& Maritz, J. S. 1982 An analysis of the linear-calibration controversy from the perspective of compound estimation. Technometrics 24, 235-242. (Minor correction in Technometrics 27, 445.)

Martinelle, S. I 970 On the choice of regression in linear calibration. Comments on a paper by R. G. Krutchkoff. Technometrics 12, 157-161.

Middleton, A. C. \& Rovers, F. A. 1976 Average pH. J. Wat. Pollut. Control Fed. 48, 395-396.

Oksanen, J., Läära, E., Huttunen, P. \& Meriläinen, J. 1988 Estimation of pH optima and tolerances of diatoms in lake sediments by the methods of weighted averaging, least squares and maximum likelihood, and their use for the prediction of lake acidity. J. Paleolimnol. 1, 39-49.

Payne, C. D. (ed.) I 986 The GLIM System Release 3.7\%. Oxford: Numerical Algorithms Group.

Picard, R. R. \& Cook, R. D. 1984 Cross-validation of regression models. J. Am. Statist. Ass. 79, 575-583.

Prentice, I. C. I980 Multidimensional scaling as a research tool in Quaternary palynology: a review of theory and methods. Rev. Palaeobot. Palynol. 31, 71-104.

Renberg, I. \& Hellberg, T. I 982 The $\mathrm{pH}$ history of lakes in southwestern Sweden, as calculated from the subfossil diatom flora of the sediments. Ambio 11, 30-33.

Snee, R. D. 1977 Validation of regression models: methods and examples. Technometrics 19, 415-428.

Stone, M. 1974 Cross-validatory choice and assessment of statistical predictions (with discussion). Jl R. statist. Soc. B 36, 111-147.

ter Braak, C. J. F. 1985 Correspondence analysis of incidence and abundance data: properties in terms of a unimodal response model. Biometrics 41, 859-873.

ter Braak, G. J. F. I 987 a Calibration. In Data analysis in community and landscape ecology (ed. R. H. G. Jongman, C. J. F. ter Braak \& O. F. R. van Tongeren), pp. 78-90. Wageningen: Pudoc.

ter Braak, C. J. F. $1987 b$ Unimodal models to relate species to environment. Doctoral thesis, University of Wageningen. ter Braak, C. J. F. I 988 CANOCO - a FORTRAN program for canonical community ordination by [partial] [detrended] [canonical] correspondence analysis, principal components analysis and redundancy analysis (version 2.1). Technical Report LWA-88-02, GLW, Wageningen, $95 \mathrm{pp}$.

ter Braak, C. J. F. \& Barendregt, L. G. 1986 Weighted averaging of species indicator values: its efficiency in environmental calibration. Math. Biosci. 78, 57-72.

ter Braak, C. J. F. \& Looman, C. W. N. 1986 Weighed averaging logistic regression and the Gaussian response model. Vegetatio 65, 3-11.

ter Braak, G. J. F. \& Looman, C. W. N. 1987 Regression. In Data analysis in community and landscape ecology (ed. R. H. G. Jongman, C. J. F. ter Braak \& O. F. R. van Tongeren), pp. 29-77. Wageningen: Pudoc.

ter Braak, C. J. F. \& Prentice, I. G. 1988 A theory of gradient analysis. Adv. ecol. Res. 18, 271-317.

ter Braak, C. J. F. \& van Dam, H. 1989 Inferring $\mathrm{pH}$ from diatoms: a comparison of old and new calibration methods. Hydrobiologia 178, 209-223.

Wallach, D. \& Goffinet, B. 1989 Mean squared error of prediction as a criterion for evaluating and comparing system models. Ecol. Modelling 44, 299-306.

\section{Appendix 1}

\section{Bootstrap estimation of sample-specific mean-squared error for $\mathrm{pH}$ reconstructions by weighted averaging}

The notation and bootstrap procedure are described in the main text. In addition, $\operatorname{AVE}\left(\hat{x}_{i, \text { boot }}\right)$ and $\operatorname{MS}\left(x_{i}-\hat{x}_{i, \text { boot }}\right)$ denote the mean and mean square, respectively, of the argument across all the bootstrap cycles where sample $i$ does not belong to the bootstrap training set.

The mean-squared error of the inferred $\mathrm{pH}$ of training sample $i$ is estimated by 
$\operatorname{MS}\left(x_{i}-\hat{x}_{i, \text { boot }}\right)$. This estimator has some importance; (i) it does not suffer from resubstitution bias and (ii) its mean across the training samples yields the bootstrap estimate of overall meansquared error of prediction. But the corresponding formula cannot be calculated for individual fossil samples, simply because the observed value $\left(x_{i}\right)$ is not available. To obtain a samplespecific error estimator we use the following decomposition:

$$
\operatorname{MS}\left(x_{i}-\hat{x}_{i, \text { boot }}\right)=\operatorname{MS}\left(\hat{x}_{i, \text { boot }}-\operatorname{AVE}\left(\hat{x}_{i, \text { boot }}\right)\right)+\left(x_{i}-\operatorname{AVE}\left(\hat{x}_{i, \text { boot }}\right)\right)^{2},
$$

which we write in shorthand as:

$$
v_{i}=v_{i 1}+v_{i 2} \text {. }
$$

The first part, $v_{i 1}$, can be calculated from the bootstrap cycles for each sample, both fossil and training samples. It represents the effects that the variability of the taxon parameters in the calibration function have on the inferred $\mathrm{pH}$ for sample $i$. It reduces in magnitude as the size of the training set increases. But it does so in a sample-specific way. This error component is likely to be relatively small for fossil assemblages consisting of taxa that are frequent and abundant in the training set and to be relatively large for assemblages consisting of taxa that are infrequent and rare in the training set.

The second part, $v_{i 2}$, can be calculated for the training samples only. It includes the error caused by imperfections in the calibration function, even if the parameters are known without error. Diatom assemblages vary even among lakes with the same $\mathrm{pH}$ or, conversely, because lakes with the same diatom assemblage may differ in $\mathrm{pH}$. Model specification error also enters $v_{i 2}$. By using multiple regression we investigated whether $v_{i 2}$ depends, in a systematic way, on $\mathrm{pH}$, the number of taxa, and the inhomogeneity of an assemblage. For $\mathrm{pH}$ we used a secondorder polynomial in $\operatorname{AVE}\left(\hat{x}_{i, \text { boot }}\right)$ and for inhomogeneity the variance ('tolerance') of the optima of the taxa present in the assemblage (Hill 1979). These predictors are suggested from the theory of linear (Martinelle I 970) and wA (ter Braak \& Barendregt I 986) calibration. The predictors, however, explained less than $10 \%$ of the variance of $v_{i 2}$ in the training set. Transformation of the variables (except $\mathrm{pH}$ ) to logarithms did not improve the fit. Apparently, the second error component is mainly due to other factors. For fossil samples it was therefore taken as a constant, namely the mean $v_{i 2}$ across the training set.

The above derivation ignores terms of order $1 / n_{\text {boot }}$ with $n_{\text {boot }}$ being the number of bootstrap cycles. These terms are negligible with our choice of $n_{\text {boot }}=1000$. 